\title{
Vera Trost
}

\section{Württembergische Landesbibliothek auf der Landesgar- tenschau in Bad Rappenau}

\section{9. - 20. Juli 2008 im Treffpunkt Baden-Württemberg}

\author{
Ministerium für Wissenschaft, Forschung und Kunst: \\ „Württembergische Landesbibliothek Stuttgart: \\ Weinbau in alten Büchern“"
}

Die Württembergische Landesbibliothek (WLB) ist nicht nur ein lebendiger Lernort, in dem Bücher gelesen oder ausgeliehen, elektronische Zeitschriften und digitale Informationen genutzt werden. Sie ist auch eine aktive Kultureinrichtung, weit über die Kulturmeile Stuttgarts hinaus präsent. Täglich kommen über 4.000 Junge und Alte, Schüler und Lehrer, Studenten und Professoren, Berufstätige und Senioren aus Stuttgart, der Region und der ganzen Welt. Sie finden neueste Fachinformationen oder erforschen die unschätzbar kostbaren alten Bestände der Bibliothek.

Im Weinland um Bad Rappenau zeigt die WLB wertvolle Bücher zum Thema Weinbau, darunter das Tafelwerk „Die WeinRebe und ihre Früchte" von Carl Friedrich von Gok, dem Halbbruder Friedrich Hölderlins, und die Dissertation von Theodor Heuss über den „Weinbau und Weingärtnerstand in Heilbronn a.N.“

Wie bereits 2006 in Heidenheim präsentiert sich zusammen mit der Landesbibiliothek der Börsenverein des Deutschen Buchhandels, Landesverband BadenWürttemberg e.V.

Sein Thema ist „Natur, Garten, Umwelt.“

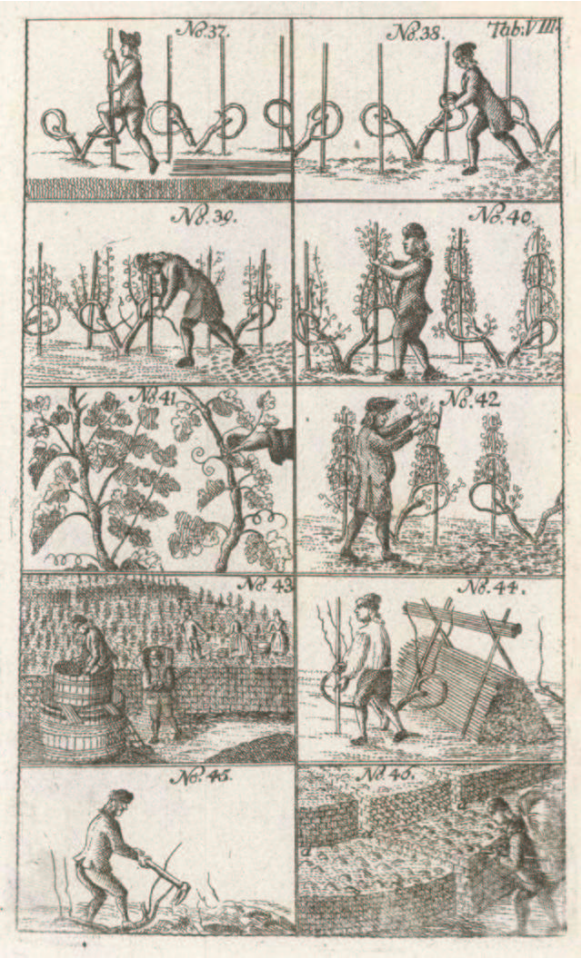

Die gemeinsame Schau wird am Mittwoch, dem 9. Juli, um 14.30 Uhr eröffnet. Für Stimmung sorgt das Turmberger-Jazz-Quartett „Heiligs Blechle“ mit Jürgen Weigel und Daniel Fütterer (Trompete) und Wolfgang Sprengel und Peter Wüstner (Posaune) mit einem anschließenden Konzert. 